Saudi Journal of Humanities and Social Sciences

Abbreviated Key Title: Saudi J Humanities Soc Sci

ISSN 2415-6256 (Print) | ISSN 2415-6248 (Online)

Scholars Middle East Publishers, Dubai, United Arab Emirates

Journal homepage: https://saudijournals.com/sjhss

Original Research Article

\title{
Teachers' Knowledge and Opinions toward Integrating Children with Autism Spectrum Disorder in Mainstream Primary School in Jeddah, Saudi Arabia
}

\author{
Amal I. Khali1 ${ }^{1 \& 2^{*}}$, Azzah Salman ${ }^{2}$, Rawan Helabi $^{2}$, Meead Khalid ${ }^{2}$ \\ ${ }^{1}$ Professor Psychiatry and Mental Health Nursing at Menoufyia University, Egypt \\ ${ }^{2}$ King Saud Bin Abdul Aziz University for Health Sciences, College of Nursing, Prince Mutib Ibn Abdullah Ibn Abdulaziz‘ Ar Rimayah, Riyadh \\ 14611, Saudi Arabia
}

DOI: $\underline{10.36348 / \text { sjhss.2020.v05i06.004 }}$
*Corresponding author: Amal I. Khalil

Abstract

Background: Autism is a neurodevelopmental disorder that affects communication, behavior, and social interaction. Autism's estimated prevalence among children was about a $15 \%$ percent increase in incidence .Positive teacher attitudes are a vital indicator of the successful education of autistic children. The current study aimed to assess the knowledge and opinions of elementary school teachers toward integrating autistic children in their regular classrooms. Methodology: a descriptive cross-sectional correlational survey research design was used to include 79 elementary school teachers recruited conveniently from two schools located in Jeddah, Saudi Arabia. Two reliable and valid tools were used including autism knowledge and opinion scale in addition to behavioral strategies used by the teachers when they are handling autistic children. Findings: The mean age of respondents were 29.2 years, $86.1 \%$ having a bachelor's degree, and only $41.8 \%$ having training and experience with ASD. Most respondents $82,3 \%$ had poor knowledge, compared with only $2.5 \%$ had good knowledge. Only $40.5 \%$ had positive opinions about ASD integration. Additionally, there is no significant association between the demographic background of the respondents, their knowledge and opinions except for their teaching experiences at $\mathrm{P} \geq 0.05$. Conclusion: The present study concluded and highlighted the inadequate knowledge level of ASD and unfavorable opinions of teachers toward integrating autistic children due to lack of training and attending workshops to improve their qualifications. Therefore, more efforts are required to further enhance the understanding of autism among all teachers who handling those students who are urgently needed.

Keywords: Autism, children, elementary schools, teachers, knowledge.

Copyright @ 2020: This is an open-access article distributed under the terms of the Creative Commons Attribution license which permits unrestricted use, distribution, and reproduction in any medium for non-commercial use (NonCommercial, or CC-BY-NC) provided the original author and source are credited.

\section{BACKGROUND}

Being autistic is not all about the struggles and impossible challenges, but it is also, about how the autistic child sees things differently than the normal one. One of these good things is that children with autism may not always communicate verbally, but they communicate on their way, and talking is not the only way to communicate, they also have strong attention to details, process and sensory input which are different than normal kids [1]. Autistic children need a special way of treatment from their parents and teachers. However, the autism community in Saudi Arabia lacks important points, which affects the achievement of the ideal environment for autistic. There are no special schools in the management of autism spectrum disorders but the available schools or centers usually integrated different intellectual disorders in one class.
Besides, the teachers who are working in these schools are not specialized in the management of autistic disorders children, which makes it difficult for them to teach and deal with them effectively and competently [1].

Autism is a neurodevelopmental disorder that affects communication, behavior, and social interaction. "Autism" is a Greek word divided into two words autos (self) and ism (action) which means a developmental disability mainly impacting the normal development of the brain in three areas which are: behavior, verbal and non-verbal communication, and social interaction. It appears from the first three years of life, and it is a lifelong disorder [2]. The early signs of autism Spectrum Disorder (ASD) can be detected from six to eighteen months, and these indicators are as the followings: absence of joyful expression, no sharing of 
sound or smiles, showing no response when someone calling by his/her name, and didn't say two wards at one year old. Additionally, other indicators are in form of poor eye contact, attachment to one object, person or dress and lines up toys, other objects which indicate that the child does not know how to play with toys, and always convey a lack of interest [3]. Autism Spectrum Disorder (ASD) could diagnose through a two-stage process. The first stage is developmental screening; it focuses on detecting any delay or disabilities in basic skills such as communication, learning, and behaviors. All children who are between nine to thirteen months should be screened during this period, especially children who have high risk, such as low birth weight (LBW), preterm before 26 weeks, and first-degree relatives. The second stage is a comprehensive diagnostic evaluation. It includes interviewing the parents and includes additional tests such as vision and hearing screening, neurological testing, genetic testing, and another medical testing. If the child needs further assessments and diagnosis, he can be referred to as Pediatrician, Psychologists or Psychiatrists, or Neurologists [4].

Autism Spectrum Disorders (ASDs) caused by many factors. Mutation besides, environmental which can increase. Some environmental factors can reduce or increase the risk of getting Autism Spectrum Disorder (ASD) such as certain medications, viral infections, complications during pregnancy [5]. Autism Spectrum Disorder can be treated by a combination of two therapies which are pharmacological interventions (antipsychotics, beta-blockers, and antidepressants), and behavioral intervention modification techniques, and Contingency management [6].

Both and Ainscow [7] cited in Al-Saleh [8], defined 'inclusion' as the process of responding to and addressing the diverse needs of all children by increasing participation in culture, communication and learning and by decreasing the separation between children with and without special educational needs. There are no data that show the specific percentages of children with ASD in Saudi Arabia [9]; however, there are 925 male students with ASD and 437 female students with ASD served by the education system (Ministry of Education, 2012, cited in Alnemary et al., [9]. Most children with ASD are educated in private schools in Saudi Arabia [10].

On the other hand, the CDC updated that autism's estimated prevalence among children about a $15 \%$ percent increase in prevalence: 1 in 59 children, from 1 in 68 two years ago [11]. "A research study was conducted using the electronic library of King Saud Bin Abdulaziz University for Health Sciences, Riyadh, Saudi Arabia to find out epidemiology of Autism in Gulf countries (Saudi Arabia, UAE, Kuwait, Bahrain, Qatar, Oman), and they found that epidemiological research into autism in the GCC is relatively new, and the burden of autism in this part of the world is still unclear, however, they concluded that consanguinity and multiparty is common. Prevalence of ASD was 1.4 per 10,000 in Oman, and 29 per 10,000 in UAE and 4.3 per 10,000 in Bahrain (4) Male gender and history of developmental delay were significantly associated with autism prevalence. Consanguinity was present in $28.6 \%$ of Saudi patients" [12]. Autistic children have another perspective of how they see the world and that can lead them to be anxious and some triggers increase their level of anxiety. Sudden changes in their routine are considered as one of the triggers factors [13]. Other triggers are unstructured time while they are waiting for the bus, sensory issues such as (crowd, noise, and smell... etc.) Indiana Resource Center for Autism 2012 [14]. Until 2010, children with ASD were excluded from regular schools because there was a lack of understanding and knowledge regarding ASD [15]. Recent studies have indicated that the number of students with ASD has increased in mainstream schools [16]; however, the services provided to these children in the KSA are insufficient [9].

Positive teacher attitudes are a vital indicator of the successful education of children with disabilities, including those with autism spectrum disorders (ASDs) [17]. However, the severity and pervasiveness ASD often leads to the teaching and inclusion of this group of pupils to be seen as especially complex [18]. Even teachers of recognized professional competence often consider themselves less able to deal with these students than with those with any other form of special needs. Therefore, teacher training also has a powerful influence on the development of attitudes toward inclusion, especially when it incorporates related and specific professional abilities [19].

According to a study conducted with 1430 teachers indicated that three types of resources were deemed necessary including training, support from a team of experts, and support in the classroom [20, 21]. Teacher training is particularly important to orient about the specific nature of the needs of these students and the prevailing misconceptions surrounding autism. Previous research has shown the necessity of updating and expanding on teachers' knowledge base on autism. In a related study, Jennett et al., [22] explored the professional self-efficacy and burn-out in teachers working with these Autism Research and Treatment children.

Moreover, Simpson, Boer-Ott, and SmithMyles [18] and Alsaleh [23], indicated that when teachers are prepared to teach students with ASD in the context of a group effort with special education teachers and with other additional resources it will be another relevant factor to develop knowledge and positive attitudes of teachers handling children with ASDs. Many conducted researches indicated that teachers 
usually mentioned their constant need to correct and update their misconception about their perception of autism [24, 17, 25-27, 13]

On average, the lack of ASDs specialized schools in Saudi Arabia hindered those children to be well treated and decrease the creativity they have. Additionally, the Saudi Arabian teachers' qualifications and competencies in special education is an important issue since their significant role in teaching the autistic children when they were included in their regular classrooms [12]. Moreover, a study conducted by Abdulhade et al., [28] Jeddah, Saudi Arabia supports the fact that Saudi teachers need more programs to improve their knowledge to correct the misconception about the nature of ASDs, and training essential behavioral strategies to deal effectively with children challenging behaviors. Therefore, this study will be conducted to assess and highlight the level of knowledge, and opinions toward inclusion of ASDs children within their regular classes.

\section{AIM OF THE STUDY}

The study aimed to assess the knowledge and attitudes of elementary school teachers toward integrating children with autism spectrum disorder (ASDS). More specifically, the current study was intended to:

1. Assess the knowledge, and opinions of teachers toward integrating children with autism spectrum disorder (ASDS) in mainstream primary school.

2. Examine the association between teachers' demographic background and their knowledge, and attitude toward integrating children with autism spectrum disorder (ASDS).

\section{Research Questions}

The present study was planned to answer the following questions:

1. What is the knowledge, and attitudes of teachers integrating children with autism spectrum disorder (ASDS)?

2. What is the association between teachers' demographic details and their knowledge, and attitude of teachers integrating children with autism spectrum disorder (ASDS)?

\section{Significance of the Study}

The updated prevalence of autism was estimated among children by about a $15 \%$ increase in prevalence: 1 in 59 children, from 1 in 68 two years ago [11]. A study was conducted using the electronic library of King Saud Bin Abdul-Aziz University for Health Sciences, Riyadh, Saudi Arabia to find out epidemiology of Autism in Gulf countries (Saudi Arabia, UAE, Kuwait, Bahrain, Qatar, Oman), and they reported that the epidemiological research in autism in the GCC is relatively new, and the burden of autism in this part of the world is still unclear, however, they concluded that consanguinity and multiparty is common. The prevalence of ASD was 1.4 per 10,000 in Oman, and 29 per 10,000 in UAE, and 4.3 per 10,000 in Bahrain. Meanwhile, male gender and history of developmental delay were significantly associated with autism prevalence. Consanguinity was present in $28.6 \%$ of Saudi patients" [12]. Additionally, Hasan, Halder, \& Debnath [29], reported that inclusion has become an important issue and is often discussed among educators, parents, and professionals from different disciplines. And a more inclusive environment will enable children with special needs to get their right to be a part of the community. Although inclusion in the KSA has been discussed and applied within mainstream schools, there are challenges related to inclusion. Avramidis, Bayliss and Burden [30] showed that one of the main barriers to inclusive education for children with special needs is teachers' attitudes; positive teacher attitudes are a vital indicator of the successful education of children with disabilities, including those with autism spectrum disorders (ASDs) [17]. However, in the KSA, few studies have discussed this issue, which highlights the importance of this study. To the best of our knowledge, the previous studies which were conducted in Saudi Arabia focused only on estimating the prevalence and severity of ASDs. Moreover, the lack of ASDs specialized schools in Saudi Arabia hindered those children to be well treated and decrease the creativity they have. Additionally, the Saudi teachers' qualifications and competencies in special education is an important issue since their significant role in teaching the autistic children when they were included in their regular classrooms [12]. However, the severity and pervasiveness ASD often leads to the teaching and inclusion of this group of pupils to be seen as especially complicated [18]. Therefore, the researchers think about assessing the level of knowledge of mainstream primary school teachers about autism and exploring their opinions toward the inclusion of autistic children within their regular classes. Hence the findings of this research will contribute to the body of knowledge of ASD and highlight the importance of educational interventions necessary for appropriate qualifications of the general education elementary school teachers to improve their knowledge, and attitudes toward integrating ASDs children in normal classes.

\section{METHODOLOGY Research Design}

A descriptive cross-sectional correlational survey research design was used to achieve the objectives of the current study.

\section{Research Setting and Population}

The study was conducted at 4 Primary Schools located at Jeddah. They are Almaarif School which is a non-governmental, started in 2005, and it involves kindergarten, elementary, and high school levels. In addition to the Help Center which is located at Jeddah, KSA. Other schools were Dar Aleizama, Dar Al Feker, and al Thanya for special education school. Those 
schools serving autistic children only in kindergarten and elementary level education. The total number of teachers in these 4 schools was eighty-three teachers of special and general education was working in target schools located at Jeddah with inclusion criteria of must have autistic children in their classes.

\section{Sampling and Sampling Techniques}

All teachers with inclusion criteria for handling the elementary level and have children diagnosed with autism spectrum disorders and willing to participate in the study were contacted by using a convenient sampling technique. Accordingly, the total numbers are nearly 45 teachers working at Almaarf School and 38 from Dar Aleizama, Dar Al Feker, and al Thanya for special education school. Margin error of 5 $\%$, confidence interval of $95 \%$, hence the minimum sample size for this study was 79 teachers.

\section{Data Collection Process}

Once the proposed study was approved from KAIMRC and IRB, a letter was submitted to the principles of the selected schools for arrangement and permission to start data collection the data were collected during the academic year 2019/2020. The participants were asked to sign the informed consent form before filling the questionnaires.

\section{Data Collection Methods}

The tool consisted of 2 main parts:

1. Demographic and personal characteristics that enquire teachers about age, level of education, years of experience (general and special education) and did they have autistic children or attend any training workshop in dealing with autistic children.

2. The second section is the Knowledge of Autism Spectrum Disorders, this scale was adapted from Stone [31], Shah [32], and Furnham and Buck [33]. The scale contains 15 items proposed to measure one's knowledge of ASD in three areas: diagnosis and symptomatology; treatment; and etiology. Knowledge items were the questions in this section are presented as True/False statements; however, a 'Don't Know' option was included and respondents were instructed to select this response rather than guess. Internal consistency of this scale is adequate in the study $(\alpha=.862)$.

3. Correct responses were added and divided by the total items 15 and then converted into a percentage out of 100 . The percentages were divided into the following ranging: $80-100 \%$ Very good knowledge, 70-80\%- Good Knowledge, 60-70\%- Satisfactory knowledge while $>60 \%$ - was given to poor knowledge.

4. The $3 \mathrm{~d}$ Section is Opinions about Inclusive Education, this scale was adapted from McGregor and Campbell [24], Furnham and
Buck [33], Praisner [34], and Stone [31]. The tool contains 27 Likert-type scale items. Six response choices range from strongly agree to strongly disagree, and a seventh option, "No opinion or neutral," is available. On eleven items, respondents evaluate whether various factors (e.g., the severity of disability) are important for successful inclusion. Eight statements measure participants' attitudes towards inclusion in general and inclusion of students with ASD in particular. Additionally, four items were selected to allow comparison of attitudes towards disabilities other than ASD. On these four items, the disability identified was changed to either ADHD or Special Education Needs. Scoring the education section, was eight items which are 2 , $8,18,21,22,23,25$, and 27) comprised of an Attitude toward ASD Inclusion Total Score (ATT). Responses to items 21 and 23 were reverse scored such that positive attitudes reflected in lower scores. Scores for ATT could range from eight to 56. Scores falling between 8 and 24 reflect positive attitudes (average score of 3 or below, suggesting slightly agree or stronger); scores between 40 and 56 reflect negative attitudes (average score of 5 or higher, suggesting slightly disagree or stronger); and scores falling between 24 and 40 represent attitudes that are neither positive nor negative. Cronbach's index of internal consistency for this scale was .071.

\section{Reliability and Validity}

The instruments were translated into Arabic language and back-translated into the English language. Back translation aimed at verifying whether the translation covers all aspects of the original English version of the questionnaire or not. Then to ensure the face validity and reliability of the final translated Arabic version of the questionnaire was evaluated by a panel of experts who were selected based on their qualifications and experience in nursing research and education. Then, the tools were piloted and tested by 10 participants to identify ambiguities in questions, the time required for completing the questionnaire, and any difficulties that might be encountered by the participants in reading or understanding the questionnaire after receiving the official approval to conduct the study. The reliability coefficient retest was calculated and reported to be .087 and .074 for knowledge and opinions scales respectively.

\section{Data Analysis}

The data were coded and analyzed using SPSS version 21.0. Data were presented using descriptive statistics for discrete variables in the form of frequencies and percentages, and for interval and ratio variables in the form of means and standard deviations. Participants' socio-demographic. Knowledge and attitudes differences were analyzed by using Pearson 
correlation test and the significance level was tested at $\mathrm{p}<0.05$

\section{Ethical Considerations}

The study was approved by the Research Unit at the College of Nursing, Jeddah, KAIMRC, and IRB. Then the approval letter was submitted to the principles of each school. After that, study subjects were approached for explaining the purposes and the procedure of the study. Subjects were informed that participation in the study was voluntary and they can withdraw without any penalty at any time. They were assured that their answers will be kept anonymous during the study and that their data will be kept confidential.

\section{FINDINGS}

\section{Demographic details}

Table-1 showed the distribution of studied respondents according to their demographic characteristics. The mean age of teachers, from a total of $\mathrm{N}=79$ were: $29.2 \pm 6.0$, the majority $(86.1 \%)$ had a bachelor's degree in education, $58.2 \%$ was qualified in teaching children with special education and less than half $(41.8 \%)$ attended special training workshops. While, more than half $(51.1 \%)$ have no teaching experiences with autistic children.
Table-1: Distribution of studied respondents according to their demographic characteristics. $(\mathrm{N}=79)$

\begin{tabular}{|l|l|l|}
\hline Variable & $\mathbf{N = 7 9}$ & \multicolumn{1}{|c|}{$\%$} \\
\hline Age & \multicolumn{2}{|l|}{$\mathbf{M}$ SD 29.2 \pm 6.0} \\
\hline Qualification & \multicolumn{1}{|l|}{} \\
\hline Diploma & 7 & 8.8 \\
\hline Bachelor & 68 & 86.1 \\
\hline Master & 3 & 3.7 \\
\hline Special & 1 & 1.2 \\
\hline Special education ASD & & \\
\hline Yes & 46 & 58.2 \\
\hline No & 33 & 41.8 \\
\hline Training ASD & & \\
\hline Yes & 33 & 41.8 \\
\hline No & 46 & 58.2 \\
\hline Experience ASD & & \\
\hline Yes & 38 & 48.1 \\
\hline No & 41 & 51.1 \\
\hline
\end{tabular}

\section{Behavioral Strategies}

According to Figure-1 which displayed the behavioral strategies used by teachers with autistic children. The most common strategy used by respondents was a visual activity- $72.2 \%$; followed by $63.3 \%$ using verbal reinforcement and $55.6 \%$ used social stories as behavioral strategies for teaching autistic children. On the other hand, $17.7 \%$ mentioned that they used other strategies without reporting the actual type of strategies.

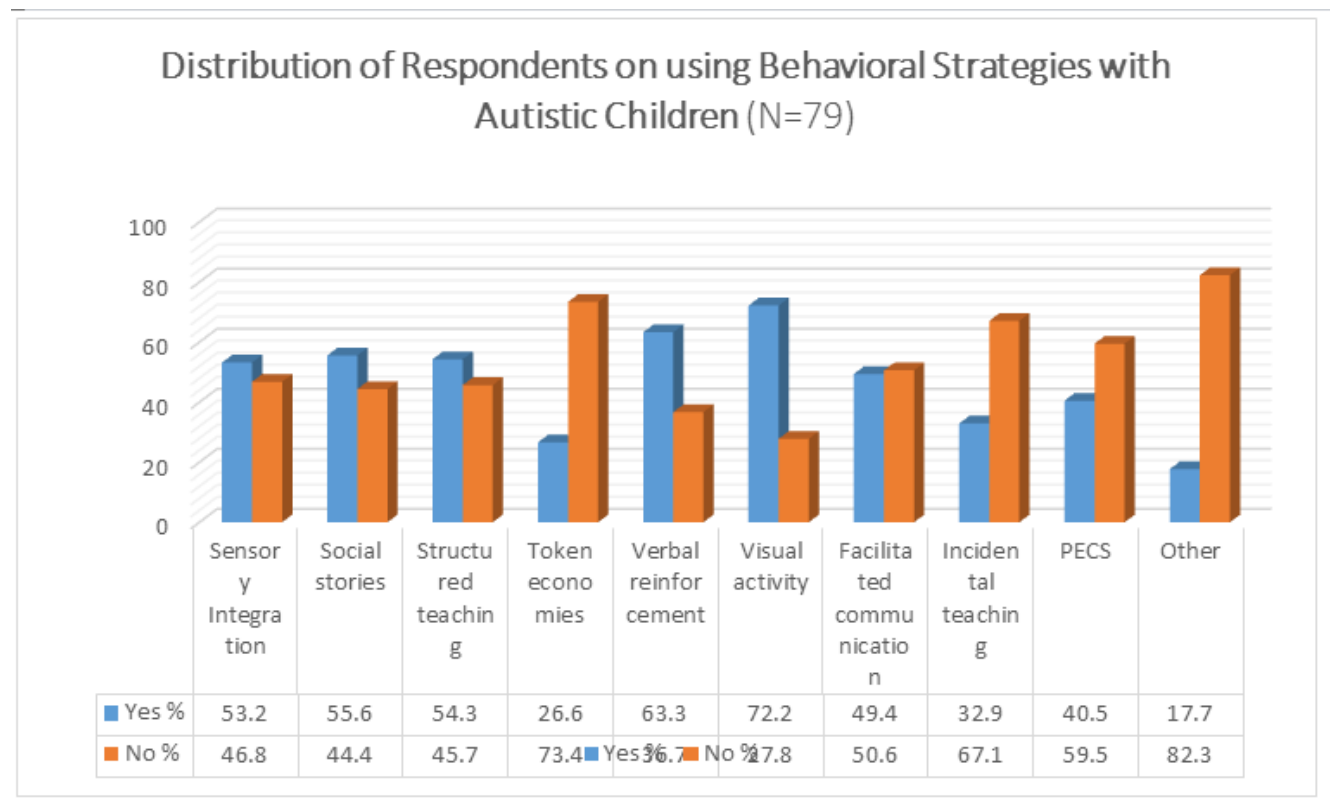

Fig-1: Behavioral strategies

\section{Knowledge about ASD}

Figure-2 exhibited a knowledge level of ASD among teachers. Surprisingly, the majority $(82.3 \%)$ had poor knowledge followed by only $15.2 \%$ had satisfactory compared by only $2.5 \%$ good knowledge and $0.0 \%$ didn't rank on a very good knowledge level. 


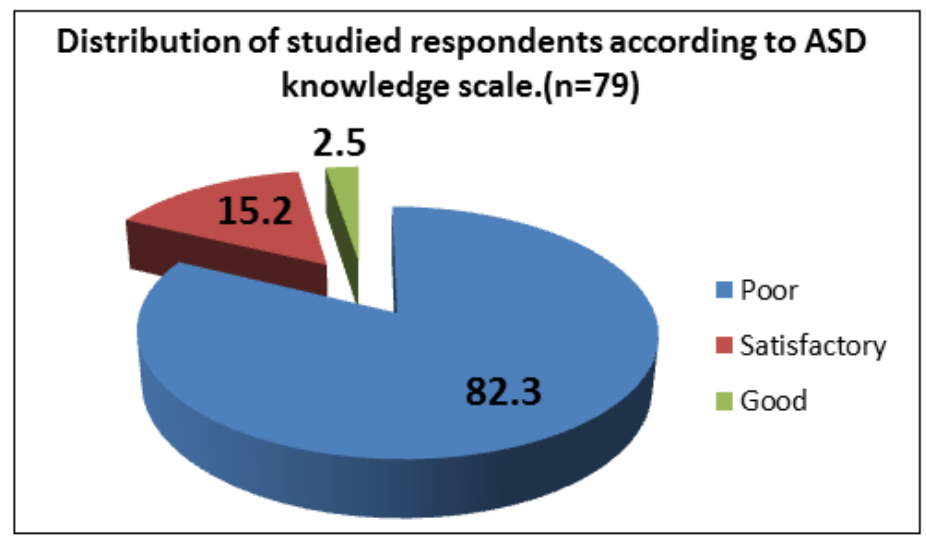

Fig-2: ASD Knowledge

Table-2 showed the distribution of the studied sample on their knowledge items of ASD. According to the individual items for knowledge, the highest-scoring knowledge item was Behaviour therapy is an intervention most likely to be effective for children with $A S D s-\mathrm{N}=67(84.8 \%)$ answered this item correctly. The second highest knowledge item was $\mathrm{N}=60(75.9 \%)$, most children with ASD have special talents or abilities. The third highest knowledge item was $\mathrm{N}=52$ 65.8\%)" with proper intervention, most children with an ASD will eventually outgrow the disorder.
Besides, the lowest-scoring knowledge item was $\mathrm{n}=56(70.9 \%) "$ The diagnostic criteria for Asperger's syndrome are identical to high functioning autism. The second-lowest scoring item was $N=$ $60(75.9 \%)$ "Children with ASD are very similar to one another. The third scoring item was $N=53$ (67.1\%) "Traumatic experience very early in life can cause an ASD.

Table-2: Distribution of studied sample on their knowledge of ASD (N=79)

\begin{tabular}{|l|l|l|l|}
\hline No. & Item & $\begin{array}{l}\text { Correct } \\
\boldsymbol{f}(\mathbf{\%})\end{array}$ & $\begin{array}{l}\text { Incorrect } \\
\boldsymbol{f}(\boldsymbol{\%})\end{array}$ \\
\hline 1 & $\begin{array}{l}\text { The diagnostic criteria for Asperger's Syndrome are identical to high functioning } \\
\text { Autism. }\end{array}$ & $23(29.1 \%)$ & $56(70.9 \%)$ \\
\hline 2 & ASDs are developmental disorders & $35(44.8 \%)$ & $44(55.2 \%)$ \\
\hline 3 & Genetic factors play an important role in the causes of ASDs. & $31(39.2 \%)$ & $48(60.8 \%)$ \\
\hline 4 & ASDs exist only in childhood. & $26(32.9 \%)$ & $53(67.1 \%)$ \\
\hline 5 & Behavior therapy is an intervention most likely to be effective for children with ASDs & $67(84.8 \%)$ & $12(15.2 \%)$ \\
\hline 6 & Children with ASDs are very similar to one another. & $19(24.1 \%)$ & $\mathbf{6 0}(\mathbf{7 5 . 9 \%})$ \\
\hline 7 & Early intervention demonstrates no additional benefit to children with an ASD & $26(32.9 \%)$ & $53(67.1 \%)$ \\
\hline 8 & $\begin{array}{l}\text { If an intervention works for one child with an ASD, it will definitely work for another } \\
\text { child with an ASD. }\end{array}$ & $15(18.9 \%)$ & $\mathbf{6 4}(\mathbf{8 1 . 1 \%})$ \\
\hline 9 & Medication can alleviate the core symptoms of ASDs. & $36(45.6 \%)$ & $43(54.4 \%)$ \\
\hline 10 & Most children with ASDs have cognitive abilities in the intellectually disabled range. & $40(50.6 \%)$ & $39(49.4 \%)$ \\
\hline 11 & Most children with ASDs have special talents or abilities. & $60(75.9 \%)$ & $19(24.1 \%)$ \\
\hline 12 & In many cases, the cause of ASDs is unknown. & $42(53.2 \%)$ & $37(46.8 \%)$ \\
\hline 13 & $\begin{array}{l}\text { The core deficits in ASDs are Impaired Social Understanding, Language Abnormalities, } \\
\text { and Impaired Sensory Functioning. }\end{array}$ & $46(58.3 \%)$ & $33(41.7 \%)$ \\
\hline 14 & Traumatic experiences very early in life can cause an ASD. & $26(32.9 \%)$ & $53(67.1 \%)$ \\
\hline 15 & $\begin{array}{l}\text { With proper intervention, most children with an ASD will eventually "outgrow" the } \\
\text { disorder. }\end{array}$ & $52(65.8 \%)$ & $27(34.2 \%)$ \\
\hline
\end{tabular}

Figure-3 displayed the distribution of studied respondents according to their ASD Opinions Scale $(\mathrm{N}=79)$. Concerning the opinion regarding ASD, respondent's opinions, the highest-scoring item related to opinions had a mean of $4.8 \pm 1.9$, related to the help of auxiliary teaching professionals, is an important factor in the successful inclusion of a student with an ASD, and the lowest-scoring item regarding opinion with a mean of $3.8 \pm 1.7$ was Only teachers with extensive special education experiences can be expected to deal with students with an ASD in a school setting. 


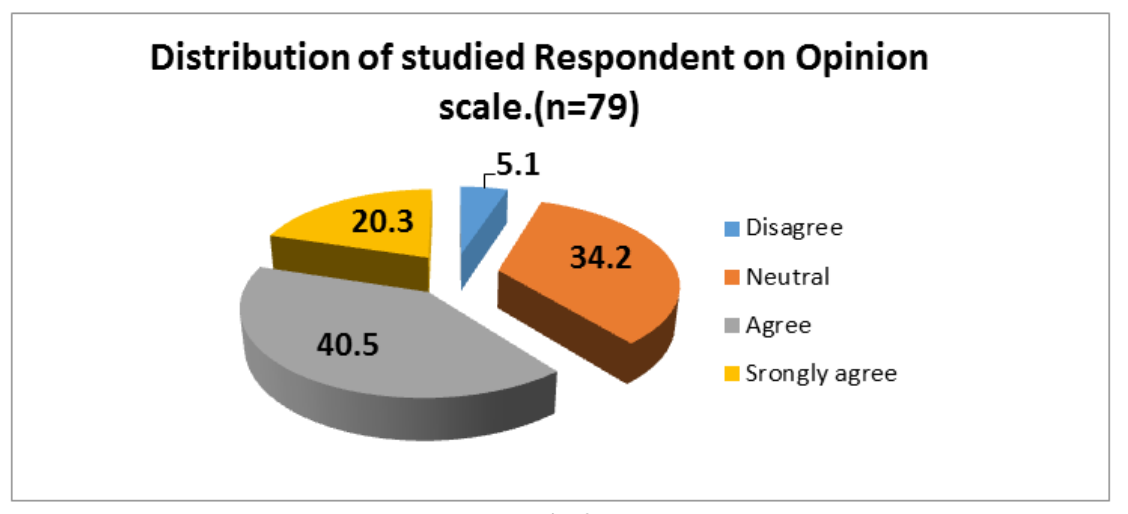

Fig-3

Distribution of Studied Teachers according to their Opinion about ASD integration (N=79)

\begin{tabular}{|c|c|}
\hline $\begin{array}{l}\text { Variables } \\
1-\text { The severity of the disability is an important factor in the successful inclusion of a student with ASD }\end{array}$ & $\begin{array}{l}\mathrm{M} \pm \mathrm{SD} \\
4.6 \pm 1.3\end{array}$ \\
\hline 2- Children with an ASD should be integrated into general education settings. & $3.8 \pm 1.8$ \\
\hline $\begin{array}{l}\text { 3- The help of an auxiliary teaching professional (i.e. paraprofessional) is an important factor in the } \\
\text { successful inclusion of a student with an ASD. }\end{array}$ & $4.9 \pm 1.9$ \\
\hline $\begin{array}{l}\text { 4- The academic ability of the student is an important factor in the successful inclusion of a student } \\
\text { with an ASD. }\end{array}$ & $4.3 \pm 1.5$ \\
\hline $\begin{array}{l}\text { 5- The severity of the disability is an important factor in the successful inclusion of a student with an } \\
\text { ASD. }\end{array}$ & $4.3 \pm 1.6$ \\
\hline 6- The student's personality is an important factor in the successful inclusion of a student with an ASD. & $4.1 \pm 1.6$ \\
\hline 7- The attitude of the staff is an important factor in the successful inclusion of a student with an ASD. & $4.1 \pm 1.6$ \\
\hline 8- All students with an ASD should be included in general education settings & $4.6 \pm 1.7$ \\
\hline 9- Children with special educational needs should be integrated into general education settings. & $4.0 \pm 1.8$ \\
\hline 10- One on one intervention is an important factor in the successful inclusion of a student with an ASD. & $3.9 \pm 1.5$ \\
\hline $\begin{array}{l}\text { 11- Encouraging students with an ASD to interact with typically developing peers is an important } \\
\text { factor in the successful inclusion of a student with an ASD. }\end{array}$ & $4.8 \pm 1.6$ \\
\hline $\begin{array}{l}\text { 12- he use of reinforcement schedules is an important factor in the successful inclusion of a student } \\
\text { with an ASD. }\end{array}$ & $4.3 \pm 1.3$ \\
\hline $\begin{array}{l}\text { 13- Medication and drug therapy is an important factor in the successful inclusion of a student with an } \\
\text { ASD. }\end{array}$ & $4.6 \pm 1.6$ \\
\hline 14- Children with ASD should be integrated into general education settings. & $3.9 \pm 1.2$ \\
\hline $\begin{array}{l}\text { 15- Only teachers with extensive special education experience can be expected to deal with students } \\
\text { with special education needs in a school setting. }\end{array}$ & $4.5 \pm 1.6$ \\
\hline $\begin{array}{l}\text { 16- The attitude of the staff is an important factor in the successful inclusion of a student with special } \\
\text { needs. }\end{array}$ & $4.2 \pm 1.7$ \\
\hline $\begin{array}{l}\text { 17- Only teachers with extensive special education experience can be expected to deal with students } \\
\text { with ASD in a school setting. }\end{array}$ & $3.8 \pm 1.7$ \\
\hline 18- Inclusive education enhances the learning experience of students with disabilities. & $4.1 \pm 1.8$ \\
\hline $\begin{array}{l}\text { 19- The severity of the disability is an important factor in the successful inclusion of a student with } \\
\text { special needs. }\end{array}$ & $3.9 \pm 1.5$ \\
\hline $\begin{array}{l}\text { 20- Only teachers with extensive special education experience can be expected to deal with students } \\
\text { with ADHD in a school setting. }\end{array}$ & $4.3 \pm 1.7$ \\
\hline 21- Students with classic autism are too impaired to benefit from the activities of a regular school. & $3.9 \pm 1.7$ \\
\hline 22- A good general education teacher can do a lot to help a student with an ASD. & $3.9 \pm 1.7$ \\
\hline 23- No discretionary financial resources should be allocated for the inclusion of students with an ASD. & $4.1 \pm 1.9$ \\
\hline 24- The attitude of the staff is an important factor in the successful inclusion of a student with ASD. & $4.7 \pm 1.6$ \\
\hline 25- Students without disabilities can benefit from contact with students with ASD. & $4.1 \pm 1.6$ \\
\hline $\begin{array}{l}\text { 26- Special schools specifically designed for their needs are the most appropriate placement for } \\
\text { students with ASD. }\end{array}$ & $4.0 \pm 1.6$ \\
\hline 27- Children with an ASD need to receive special education services at school. & $4.6 \pm 1.5$ \\
\hline Overall & $4.2 \pm 1.6$ \\
\hline
\end{tabular}


Association between ASD knowledge and opinions with the basic characteristics of the teacher:

Table-4 presented that there was no significant correlation between ASD knowledge and opinions with the demographic characteristics of the teachers at $\mathrm{P} \geq 0.05$. While teaching experiences had a significant relationship with their opinion scale at $\mathrm{p}=0.021$.

Table-4: Association between ASD knowledge and opinions with the basic characteristics of the teacher (N=79)

\begin{tabular}{|l|l|l|}
\hline Variable & ASD Knowledge P-value & ASD Opinions P-value \\
\hline Qualification & 0.972 & 0.593 \\
\hline Special Education & 0.961 & 0.633 \\
\hline Training & 0.427 & 0.229 \\
\hline Experience & 0.126 & $0.021 *$ \\
\hline \multicolumn{2}{|c|}{ *significant at 5\% level }
\end{tabular}

Association between ASD knowledge and opinions with behavioral strategies

Table-5 showed that there was no significant correlation between ASD knowledge and opinions with behavioral strategies used by the teachers at $\mathrm{P} \geq 0.05$.
While three behavioral strategies were found to have a significant association with teachers' ASD opinions. They are: sensory integration (0.027), structured teaching and PECS behavioral strategies at $\mathrm{P}=0.001$.

Table-5: Association between ASD knowledge and opinions with behavioral strategies:

\begin{tabular}{|l|l|l|}
\hline Strategy & ASD Knowledge P-value & ASD Opinions P-value \\
\hline Sensory Integration & 0.966 & $0.027^{*}$ \\
\hline Social stories & 0.894 & 0.055 \\
\hline Structured teaching & 0.651 & $0.031^{*}$ \\
\hline Token economies & 0.324 & 0.208 \\
\hline Verbal reinforcement & 0.282 & 0.282 \\
\hline Visual activity & 0.764 & 0.564 \\
\hline Facilitated communication & 0.845 & 0.287 \\
\hline Incidental teaching & 0.664 & 0.085 \\
\hline PECS & 0.216 & $0.001^{*}$ \\
\hline
\end{tabular}

Association between ASD knowledge scale and respondent's opinion

Table-6 below represents the association between ASD knowledge scale and respondent's opinion, and revealed no significant association between knowledge scale except for items related to "The core deficits in ASDs are Impaired Social Understanding, Language abnormalities, and Impaired Sensory Functioning "at $\mathrm{P}=0.041$.

Table-6: Association between respondents ASD knowledge and opinions related to autistic Children integration $(\mathrm{N}=79)$

\begin{tabular}{|l|l|}
\hline Item & $\begin{array}{l}\text { P- } \\
\text { value }\end{array}$ \\
\hline 1- The diagnostic criteria for Asperger's Syndrome are identical to High functioning Autism. & 0.421 \\
\hline 2-ASDs are developmental disorders. & 0.372 \\
\hline 3-Genetic factors play an important role in the causes of ASDs & 0.320 \\
\hline 4- ASDs exist only in childhood. & 0.299 \\
\hline 5- Behaviour therapy is an intervention most likely to be effective for children with ASDs. & 0.310 \\
\hline 6-Children with ASDs are very similar to one another. & 0.396 \\
\hline 7- Early intervention demonstrates no additional benefit to children with an ASD. & 0.050 \\
\hline 8- If an intervention works for one child with an ASD, it will work for another child with an ASD. & 0.631 \\
\hline 9- Medication can alleviate the core symptoms of ASDs. & 0.680 \\
\hline 10- Most children with ASDs have cognitive abilities in the intellectually disabled range. & 0.542 \\
\hline 11- Most children with ASDs have special talents or abilities. & 0.211 \\
\hline 12- In many cases, the cause of ASDs is unknown. & 0.293 \\
\hline $\begin{array}{l}\text { 13- The core deficits in ASDs are Impaired Social Understanding, Language Abnormalities, and Impaired } \\
\text { Sensory Functioning. }\end{array}$ & $0.041^{*}$ \\
\hline 14- Traumatic experience very early in life can cause an ASD. & 0.557 \\
\hline 15- With proper intervention, most children with an ASD will eventually "outgrow" the disorder. & 0.076 \\
\hline
\end{tabular}




\section{DISCUSSION}

Disability in Saudi Arabia is perceived through the lens of Islamic Sharia, through cultural norms and also through legislation. As an Islamic community that follows the Qur'an and the Sunnah. Islam teaches that people with disabilities are to be handled with respect and equality. Therefore, it is important for school teachers who handle autistic students to obtain their knowledge about autism spectrum disorder to give proper education for them. In addition to that, to use appropriate teaching techniques with ASD children.

This current cross-sectional study was conducted in Jeddah, Saudi Arabia involved 79 teachers in different schools, and showed that the majority $82.3 \%$ have poor knowledge regarding Autism spectrum disorder the matter that is supported by many studies conducted in and outside Saudi Arabia. Likewise, Alharbi et al., [12] reported in his study which was conducted in Al-Qassim that, $51.3 \%$ of the respondents had a low level of knowledge of ASD. Moreover, Haimour and Obaidat [35] reported on their survey study conducted in the same setting of the current study (Jeddah) that, $42 \%$ of respondents had a low level of ASD knowledge. Alike with a crosssectional study which was conducted in the urban region of Oman to evaluate school teachers' awareness about ASD. 164 teachers were randomly enrolled from five schools and showed misconceptions about autism spectrum disorder among mainstream teachers in the country as well as lack of awareness. More specifically, the results of the current study indicated that $81.1 \%$ had inadequate knowledge regarding "the interventions that worked for one child with an ASD, work for another autistic child", 75.9\% indicated incorrectly that, ASDs children have similarities between each other, and $70.9 \%$ had incorrect answers about diagnostics criteria. It is worrying that the majority of primary school teachers appeared to have poor knowledge about children with autism [36], were not prepared to teach autistic children in their classroom [37-40] and felt inadequate in both teaching and dealing with students with autism [41, 42].

Additionally, the present study revealed that only $20.3 \%$ of the participants strongly agree that qualification and special education is necessary to integrate students with an autism spectrum disorder in their regular classes, and $40.5 \%$ had agreed response followed by $34.2 \%$ neutral response and $5.1 \%$ disagree to integrate those autistic children in their regular classes. Accordingly, the term "integration" means "the systematic placement of someone in something else and the completion of the subject as an independent, integral part of a larger whole" [43]. On the other hand, Zoniou-Sideri [43], claims that the term "inclusive education" is the result of academics" works to widen the term "integration", which is no longer a goal, but a means of changing social statistics, since it aims not to limit the margins of educational organizations, but to involve broader community constitutions. Similarly, AlFaiz [44] done a survey in Saudi Arabia studying the attitudes of 231 primary school tutors concerning the integration of students with autism in general education classes. The findings highlighted that the teaching framework, experiences of teaching, and also the existence of a relative with disabilities in the family greatly influenced teachers' attitudes towards autistic students.

Alhudaithi [45] had researched in Saudi Arabia as data were revealed that teachers of government schools were not supportive and had negative attitudes towards the integration of students with autism in the general classroom. In contrast, teachers at private special schools had more positive attitudes towards the inclusion of ASD children more than those teachers working in public primary schools. Besides, teachers supported the idea that inclusive classes were not suitable for students with autism, nor were they qualified enough to educate these children. Therefore, further preparation and training on the practice of integration strategies and techniques are needed, as the researcher argued. This finding should alarm the ministry of education regarding special salaries for teachers working in general schools as well as regular workshops and professional development to increase their abilities to work with ASD children in their regular classes

Moreover, the occurrence of inclusive education in Saudi Arabia is reported as it is in line with international developments. The Persons with Disabilities Act of 1995 is the first major legislation to protect the rights of individuals with disabilities. The act further emphasizes that whenever possible, students with disabilities should be educated in regular school settings. So far, despite policy initiatives, little progress has been made for these children to gain access to regular schools. In recent years, inclusive education in Saudi Arabia is moving at a fast pace in terms of new educational policies [46].

As regards the factors that can influence teachers' attitudes towards students with disabilities and/or special educational needs. Research has shown [44, 47-53, 39] that many factors can influence teachers' attitudes towards students with disabilities and special educational needs. Some of these factors are their gender, their age, their teaching experience, their previous experience with individuals with disabilities or special educational needs, their academic education, their professional training and the specialized seminars they have attended, their beliefs and the type and the severity of the students' disabilities. Similarly, the demographic characteristics of the studied teachers in the current study had no significant difference in their knowledge and opinions. Meanwhile, the association between ASD knowledge and opinions of the studied teachers with their teaching experience had a positive 
correlation with their knowledge of ASD and opinions at $\mathrm{p}=0.021$.

As regards the integration of ASD children and others with special needs. In the Saudi Community, many risk factors were reported including lack of education about disabilities and shame for having a disability and the poverty that often accompanies disability. In addition, parents of children with autism, often get information about their children's condition from non-medical sources, believing vaccinations or the evil eye caused the autism disorder. Some parents turn to religion to help their children improve. Therefore, people with disabilities are often marginalized for these various mentioned reasons besides the stigma of having a disabled child within the family. However, Saudi Arabia tends to view disability through the medical model, rather than the social model. As well as, there are few types of research relating to people with disabilities in Saudi Arabia compared to other countries. Unfortunately, there is no credible source on the national statistics of disability in Saudi Arabia.

Furthermore, the most common behavioral strategies used by respondents with autistic children were visual activity followed by verbal reinforcement and telling social stories. On the other hand, $17.7 \%$ mentioned that they used other strategies without reporting their strategies. As for the association between ASD knowledge and opinions with behavioral strategies there was no significant correlation between ASD knowledge and opinions with behavioral strategies used by the teachers at $\mathrm{P} \geq 0.05$. While three behavioral strategies were found to have a significant association with teachers' ASD opinions. They are sensory integration (0.027), structured teaching, and PECS behavioral strategies at $\mathrm{P}=0.001$. Therefore, the more the used strategies the more familiarity and applicability by the teachers. According to (Aslan, 2016) educators had little knowledge about what autism is, supported the view that students would not be able to accomplish their tasks at school and had a strong belief that children would complete their assignments better if they were involved in more physical activities rather than mental ones. Teachers working in the selected settings of the current study seem that their learning experience and professional development was ended by obtaining their Bachelor degree as more than half of the studied respondents in the current study didn't attend support or workshops group to updates their knowledge regarding the new behavioral strategies that worked with autistic children. Moreover, many teachers supported the point that inclusive classes were not suitable for autistic students, nor were they qualified enough to teach those children [45].

\section{LIMITATIONS}

Despite the result of the current study was highlighted the poor knowledge level of teachers' about ASD and the necessity of their qualification to handle the ASD children by the current study. Two limitations were reported first was the small sample size of participants due to the small number of general and specialized schools integrating children with ASD. The second was only female teachers were included due to cultural issues. Therefore, an attempt should be made to study the influence of gender on their knowledge, opinions, and used behavioral strategies.

\section{CONCLUSION}

The results of the current study discussed thus far lead to the following conclusions; the majority of studied school teachers have a relatively low level of knowledge about Autism and strongly agree that qualification and special education are necessary to integrate students with ASD in their regular classes. All demographic backgrounds had no effect on teachers' knowledge and opinions except for teaching experiences which had a positive correlation between knowledge and their opinions regarding the integration of autistic children. Additionally, visual activity, verbal reinforcement, and telling social stories were the most practical behavioral strategies used by them when dealing with autistic children. Besides, the teachers indicated the lack of opportunity to attend workshops or training programs to increase their professional development and awareness with new updates in the management of ASD children.

\section{RECOMMENDATIONS}

Based on the results of the current study which its findings support the importance of:

- Incorporating ASD training programs into teacher-training curricula either in special or general education, with regular reinforcement through an in-service training program.

- Ministry of Art and education needs to take a more proactive approach by designing and conducting specialized in-service training courses for primary school teachers to increase recognition and awareness of these disorders.

- Professional development, and training of educators handling children with ASD.

- School teachers who serve students with Autism in inclusive sittings present with a wide array of characteristics and qualifications. Also, all school teachers, regardless of specific qualifications, should receive training in educational practices needed to effectively serve this group of students.

- Future research should be directed toward conducting a similar study with large sample size and different gender as it appears as a factor that may affect knowledge, opinions, and the competency level in applying the behavioral strategies in managing children with ASD. 


\section{ACKNOWLEDGMENTS}

The success of this mini-project study would have not been possible without the following special people whom I would sincerely like to thank teachers, principals of the schools who provide the opportunity to finish this very important study.

\section{REFERENCES}

1. Ismat, H. A., Saifeldin, M. S., Abubakr, M. I., Eid, I. B., Khalid, A. I., Sara, A. M. E., \& Muhammad, A. (2019). Contamination and human health risk assessment of heavy metals in soil of a municipal solid waste dumpsite in Khamees-Mushait, Saudi Arabia. Toxin Reviews, DOI, 10(15569543.2018), 1564144.

2. Altay, M. A. (2019). Family Physicians' Awareness of Autism Spectrum Disorder: Results from a Survey Study. Open access Macedonian journal of medical sciences, 7(6), 967.

3. Carpenter, B., Happé, F., \& Egerton, J. (Eds.). (2019). Girls and autism: educational, family and personal perspectives. Routledge.

4. Centers for Disease Control and Prevention. (2012). Autism and developmental disabilities monitoring (ADDM) network. Retrieved November, 3, 2012.

5. Heimbach, J. K., Kulik, L. M., Finn, R. S., Sirlin, C. B., Abecassis, M. M., Roberts, L. R., ... \& Marrero, J. A. (2018). AASLD guidelines for the treatment of hepatocellular carcinoma. Hepatology, 67(1), 358380.

6. Reddy, U. M., Davis, J. M., Ren, Z., \& Greene, M. F. (2017). Opioid use in pregnancy, neonatal abstinence syndrome, and childhood outcomes: executive summary of a joint workshop by the Eunice Kennedy Shriver National Institute of Child Health and Human Development, American Congress of Obstetricians and Gynecologists, American Academy of Pediatrics, Society for Maternal-Fetal Medicine, Centers for Disease Control and Prevention, and the March of Dimes Foundation. Obstetrics and gynecology, 130(1), 10.

7. Ainscow, M., Dyson, A., Hopwood, L., \& Thomson, S. (2016). Primary Schools Responding to Diversity: barriers and possibilities. York: Cambridge Primary Review Trust.

8. Al-Saleh, M., (2019) Teachers' perceptions towards inclusive education for Children with Autism.

9. Alnemary, F. M., Aldhalaan, H. M., SimonCereijido, G., \& Alnemary, F. M. (2017). Services for children with autism in the Kingdom of Saudi Arabia. Autism, 21(5), 592-602.

10. Al-Zahrani, A. (2013). Prevalence and clinical characteristics of autism spectrum disorders in school-age children in Taif-KSA. International Journal of Medical Science and Public Health, 2(3), 578-582.

11. Speaks, A. (2018). CDC increases estimate of autism's prevalence by 15 percent, to 1 in 59 children. New York, USA.

12. Alharbi, K. A., Alharbi, A. A., Al-Thunayyan, F. S., Alsuhaibani, K. A., Alsalameh, N. S., Alhomaid, M. H., ... \& Hamid, P. F. (2019). School's Teachers Knowledge About Autism in Al-Badayacity, Al-
Qassim Region, Kingdom of Saudi Arabia. Materia Socio-Medica, 31(1), 4.

13. Woods, R. (2019). Demand avoidance phenomena: circularity, integrity and validity-a commentary on the 2018 National Autistic Society PDA Conference. Good Autism Practice, 20(2).

14. Levy, S. (1988). Identifying high functioning children with autism. Indiana Resource Center for Autism.

15. Almasoud, H. (2010). The education of children with autism in Saudi Arabia: a teaching guide. Special Education Department: King Saud University.

16. Alotaibi, F., \& Almalki, N. (2016). Saudi teachers' perceptions of ICT implementation for students with autism spectrum disorder at mainstream schools. Journal of Education and Practice, 7(5),

17. Robertson, K., Chamberlain, B., \& Kasari, C. (2003). General education teachers' relationships with included students with autism. Journal of Autism and developmental disorders, 33(2), 123-130.

18. Simpson, R. L., de Boer-Ott, S. R., \& Smith-Myles, B. (2003). Inclusion of learners with autism spectrum disorders in general education settings. Topics in language disorders, 23(2), 116-133.

19. Al-Shammari, Z. (2006). Special Education Teachers' Attitudes Toward Autistic Students in the Autism School in the State of Kuwait: A case study. Journal of Instructional Psychology, 33(3).

20. Werts, M. G., Wolery, M., Snyder, E. D., \& Caldwell, N. K. (1996). Teachers' perceptions of the supports critical to the success of inclusion programs. Journal of the Association for Persons with Severe Handicaps, 21(1), 9-21.

21. Tan, T. Z., Miow, Q. H., Huang, R. Y. J., Wong, M. K., Ye, J., Lau, J. A., ... \& Davidson, B. (2013). Functional genomics identifies five distinct molecular subtypes with clinical relevance and pathways for growth control in epithelial ovarian cancer. EMBO molecular medicine, 5(7), 1051-1066.

22. Jennett, H. K., Harris, S. L., \& Mesibov, G. B. (2003). Commitment to philosophy, teacher efficacy, and burnout among teachers of children with autism. Journal of autism and developmental disorders, 33(6), 583-593.

23. Alsaleh, A. (2019). Investigating instructional leadership in Kuwait's educational reform context: school leaders' perspectives. School Leadership \& Management, 39(1), 96-120.

24. Campbell, B., Mandondo, A., Nemarundwe, N., Sithole, B., De Jong, W., Luckert, M., \& Matose, F. (2001). Challenges to proponents of common property recource systems: Despairing voices from the social forests of Zimbabwe. World development, 29(4), 589-600.

25. Marks, C. (1999). The Korean of the Morning: Classic Recipes from the Land of the Morning Calm. Chronicle Books.

26. Giangreco, M. F., Edelman, S. W., Luiselli, T. E., \& MacFarland, S. Z. (1997). Helping or hovering? Effects of instructional assistant proximity on students with disabilities. Exceptional children, 64(1), 7-18. 
27. Coates, E. (2017). The Poetics of Physics in Dance. PAJ: A Journal of Performance and Art, 39(2), 7-21.

28. Tan, T. Z., Miow, Q. H., Huang, R. Y. J., Wong, M. K., Ye, J., Lau, J. A., ... \& Davidson, B. (2013). Functional genomics identifies five distinct molecular subtypes with clinical relevance and pathways for growth control in epithelial ovarian cancer. EMBO molecular medicine, 5(7), 1051-1066.

29. Hasan, M., Halder, U. K., \& Debnath, D. (2018). Inclusive education and Education for all. International Journal of Research and Analytical, 5(3):605-608.

30. Avramidis, E., Bayliss, P., \& Burden, R. (2000). Students' attitudes towards the inclusion of children with special educational needs in an ordinary school. Teaching and Teacher Education, 16(3), 277-293.

31. Stone, C. D. (1987). Earth and Other Ethics the Case for Moral Pluralism.

32. Shah, N. (2001). Contagious divides: Epidemics and race in San Francisco's Chinatown (Vol. 7). Univ of California Press.

33. Furnham, A., \& Buck, C. (2003). A comparison of lay-beliefs about autism and obsessive-compulsive disorder. International Journal of Social Psychiatry, 49(4), 287-307.

34. Praisner, C. L. (2003). Attitudes of elementary school principals toward the inclusion of students with disabilities. Exceptional children, 69(2), 135-145.

35. Haimour, A. I., \& Obaidat, Y. F. (2013). School Teachers' Knowledge about Autism in Saudi Arabia. World Journal of Education, 3(5), 45-56.

36. Geraldina, I., Rossieta, H., \& Utama, S. (2015). Motives of customer deposits window-dressing in Indonesian commercial banks. AJBA, 8(2), 67-90.

37. Baumgratz, T., Cramer, M., \& Plenio, M. B. (2014). Quantifying coherence. Physical review letters, 113(14), 140401.

38. Low, J., Yu, J., Jaroniec, M., Wageh, S., \& AlGhamdi, A. A. (2017). Heterojunction photocatalysts. Advanced materials, 29(20), 1601694.

39. Pervin, M., Hasnat, M. A., Lim, J. H., Lee, Y. M., Kim, E. O., Um, B. H., \& Lim, B. O. (2016). Preventive and therapeutic effects of blueberry (Vaccinium corymbosum) extract against DSSinduced ulcerative colitis by regulation of antioxidant and inflammatory mediators. The Journal of nutritional biochemistry, 28, 103-113.

40. Razali, A. R., \& Qin, Y. (2013). A review on micromanufacturing, microforming and their key issues. Procedia Engineering, 53, 665-672.

41. Akgul, O., Shah, N., \& Papageorgiou, L. G. (2012). Economic optimisation of a UK advanced biofuel supply chain. Biomass and Bioenergy, 41, 57-72.
42. Zahmatkesh, M., Spanjers, H. L. F. M., Toran, M. J., Blánquez, P., \& Van Lier, J. B. (2016). Bioremoval of humic acid from water by white rot fungi: exploring the removal mechanisms. $A M B$ Express, 6(1), 118.

43. Zoniou-Sideri, A. (2011). Individuals with disabilities and their education: A psychoeducational approach to integration.

44. Khamis, R. A., Daoud, H. M., Al-Faiz, M. Z., \& Sanduk, M. I. (2007). Study the Integro-Differential Equation in a Lorentzian Energy Spread Case. Engineering and Technology Journal, 25(suppl. of No. 2), 291-298.

45. Alhudaithi, G. S. S. (2015). Saudi Arabian female teachers' attitudes towards the inclusion of children with autism into mainstream classrooms (Doctoral dissertation, University of Leeds).

46. Srivastava, M., de Boer, A. A., \& Pijl, S. J. (2017). Preparing for the inclusive classroom: changing teachers' attitudes and knowledge. Teacher Development, 21(4), 561-579.

47. Avissar, G., Reiter, S., \& Leyser, Y. (2003). Principals' views and practices regarding inclusion: the case of Israeli elementary school principals. European Journal of Special Needs Education, 18(3), 355-369.

48. Center, Y., \& Ward, J. (1987). Teachers' attitudes towards the integration of disabled children into regular schools. The Exceptional Child, 34(1), 41-56.

49. Clough, P., \& Lindsay, G. (1991). Integration and the Support Service. Slough: NFER. Coates, RD (1989). The regular Education Initiative and opinions of regular classroom teachers. Journal of Learning Disabilities, 22, 532-536.

50. Eiserman, W. D., Shisler, L., \& Healey, S. (1995). A community assessment of preschool providers' attitudes toward inclusion. Journal of Early Intervention, 19(2), 149-167.

51. Finke, E. H., Finke, E. H., McNaughton, D. B., \& Drager, K. D. (2009). "All Children Can and Should Have the Opportunity to Learn": General Education Teachers' Perspectives on Including Children with Autism Spectrum Disorder who Require AAC. Augmentative and Alternative Communication, 25(2), 110-122.

52. Forlin, C. (1995). Educators' beliefs about inclusive practices in Western Australia. British Journal of Special Education, 22(4), 179-185.

53. Kofidou, C., Mantzikos, C., Chatzitheodorou, G., Kyparissos, N., \& Karali, A. (2017). Teachers' perceptions and attitudes on the inclusive education of students with Autism Spectrum Disorders (ASD):

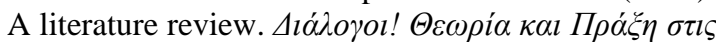

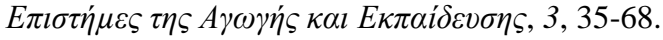

